\title{
ИРАН НА ПУТИ К КОНВЕНЦИИ О ПРАВОВОМ СТАТУСЕ КАСПИЙСКОГО МОРЯ: ПРОБЛЕМЫ РЕАЛИЗАЦИИ
}

\section{IRAN ON THE WAY TO THE CONVENTION ON THE LEGAL STATUS OF THE CASPIAN SEA: PROBLEMS OF IMPLEMENTATION \\ I. Kopylova}

Summary: the purpose of the study is to identify the historical, political, and current socio-economic conditions for the implementation (i.e., ratification) of the Convention on the legal status of the Caspian Sea by Iran. The article discusses some of the basic principles approved in the Convention, which are a continuation of the previous Soviet-Iranian agreements. On the one hand, the Convention on the legal status of the Caspian Sea becomes a starting point for developing five-party relations at a new level, expressing deep trust and political will, and lobbying for geopolitical and environmental security in the region. On the other hand, legal recognition of the Convention faces a delay in the procedure due to a number of «unfavorable» circumstances. The scientific novelty of the study is to identify the causes of socio-political instability in Iran and its significance for the process of ratification of the Convention on the legal status of the Caspian Sea. The result substantiates the prerequisites is a discrepancy of qualification of national objectives, including the primacy or delays in addressing the question of the timing of ratification of the Convention, its risks and the further practical use of the document.

Keywords: Convention on the legal status of the Caspian Sea; problem of ratification; parliamentary elections 2020 in Iran; national interests; historical and geopolitical significance of the Caspian Sea.

\author{
Копылова Ирина Александровна \\ аспирант, Кубанский государственный университет \\ irochkakostenko@gmail.com
}

Аннотация: Цель исследования - выявить историко-политические и современные социально-экономические условия для реализации (т.е. ратификации) Ираном Конвенции о правовом статусе Каспийского моря. В статье рассматриваются некоторые основные принципы, утвержденные в Конвенции, которые находят продолжение предыдущих советско-иранских договоренностей. С одной стороны, Конвенция о правовом статусе Каспийского моря становится отправной точкой в развитии пятисторонних отношений на новом уровне, выражении глубокого доверия и политической воли, лоббировании геополитической и экологической безопасности в регионе. С другой стороны, юридическое признание Конвенции сталкивается с затягиванием процедуры в связи с рядом «неблагоприятных» обстоятельств. Научная новизна исследования заключается в обнаружении причин социально-политической нестабильности в Иране, ее значении для процесса ратификации Конвенции о правовом статусе Каспийского моря. В результате обоснованы предпосылки расхождении квалификации национальных задач страны, их первостепенности или несвоевременности в контексте решения вопроса 0 сроках ратификации Конвенции, сопутствующих рисках и дальнейшей практической пользе документа.

Ключевые слова: конвенция о правовом статусе Каспийского моря; проблема ратификации; парламентские выборы 2020 в Иране; национальные интересы; историко-геополитическое значение Каспия.
A ктуальность темы исследования обусловлена промежуточным состоянием пятисторонних договоренностей, которые были достигнуты пятью прикаспийскими государствами Азербайджаном, Ираном, Казахстаном, Россией и Туркменистаном на Пятом каспийском саммите в Актау. Была принята Конвенция о правовом статусе Каспийского моря, закрепляющая основные принципы в вопросе определения его историко-правового статуса. Но вопрос ратификации документа всеми участниками и, соответственно, дальнейшая работа сторон затягивается, особенно в Иранской Республике.

Для достижения указанной цели по выявлению историко-политических и современных социально-экономических условий для реализации (т.е. ратификации) Ираном Конвенции о правовом статусе Каспийского моря необходимо решить несколько задач: во-первых, рассмотреть основные принципы, закрепленные в Конвенции 2018 г. и провести их сравнительный анализ с межгосударственными документами периода двусторонних советско-иранских договоренностей по Каспию; во-вторых, систематизировать внутриполитические и внешнеполитические условия в Иране в период 2018 - 2020 гг.; в-третьих, выявить и проанализировать причинно-следственную взаимосвязь указанных событий в контексте концепции реализации национальных интересов Ирана в отношении Каспийского моря с целью выявления вероятности ратификации документа Ираном.

С целью выявления условий, обуславливающих проблему ратификации Ираном Конвенции о правовом статусе Каспийского моря, в статье используются следующие методы исследования: историко-сравнительный, метод анализа. Системно-структурный метод применим для комплексного рассмотрения социально-политических, общественно-экономических внутренних и внешних обстоятельств, которые имели место в Иранской Республике за последние годы. 
Теоретической базой исследования являются международно-правовые документы по Каспию, составители С.С. Жильцов, И.С. Зонн [4], работы авторов В. Хоссейнзадех [13], Я.В. Манин [5], в которых рассматривается политика Ирана в Каспийском регионе, вопросы недропользования на современном этапе, актуализируется Каспий в качестве стратегически важного компонента региональной политики.

Практическая значимость исследования заключается в том, что выявляются и систематизируются возможные риски и перспективы, с которыми сталкивается Иран в своей внутренней и внешней политике, определяется практическая ценность Конвенции о правовом статусе Каспийского моря как индикатора межгосударственных отношений в регионе. Статья и ее тезисы могут быть использованы в педагогической и проектной деятельности, как для усовершенствования образовательного процесса, так и расширения проблемного историко-политического потенциала темы исследования.

В течение минувшего столетия историко-геополитический статус Каспийского моря определялся по линии Иран - Россия. Обусловленность взаимодействия двух геополитических акторов закреплялась двусторонними договоренностями в контексте имеющихся и обнаруженных ресурсов Каспия. Отталкиваясь от советскоперсидских договоренностей и комплекса принципов межгосударственного взаимодействия Советской России с Ираном в вопросе распространения государственных интересов, отметим наличие сформировавшегося и устойчивого порядка в условиях биполярного разграничения Каспия, который потерял свою актуальность и жизнеспособность вследствие исторических обстоятельств и распада Советского Союза. В контексте наличия некоторой системы взаимодействия соседних государств Каспийского региона остановимся на принципах, утвержденных (провозглашенных) в документах XX века:

1. актуальной признавалась граница между Россией и Персией, которая была установлена Разграничительной Комиссией 1881 года при некоторых оговорках [4, с. 67];

2. стороны пользовались правом свободного мореплавания по Каспийскому морю под своим флагом в равной степени [4, с. 70];

3. вопрос о праве производства лова и переработки рыбы на своих берегах определялся деятельностью специальной Смешанной Компании, организуемой правительствами обеих договаривающихся стран [4, с. 86]. При этом персидская и советская стороны договариваются о равных долях в Компании [4, с. 88];

4. торговля Советского Союза с Персией осуществлялась на основе нетто-баланса, согласно которому на основании ежегодно формируемого списка, составляемого по обоюдному двустороннему соглашению, устанавливался порядок реверсивного ввоза и вывоза товаров Союза Советских социалистических республик и Персии [4, с. 110].

Кроме того, еще один установленным принципом советско-иранского взаимодействия является взаимное предоставление режима наиболее благоприятствуемой нации в вопросах осуществления операций в области товарооборота, транзита, хранения, таможенного контроля [4, с. 115], а также в вопросах перевозки пассажиров, багажа и пр.

Шестым принципом отметим исключительное право нахождения судов договорившихся стран на всем протяжении Каспийского моря, где, более того, экипаж должен состоять только, принадлежащих к советскому или персидскому гражданству [4, с. 131].

Заметим, что данные принципы находят отражение и в настоящих достигнутых пятисторонних договоренностях. При этом последний из указанных принципов, закрепленный в Конвенции 2018 г., вызывает недоверие и домыли, противоречивую реакцию со стороны иностранных изданий. «Высокопоставленный советник Министерства иностранных дел России, который в условиях анонимности с автором сказал, что «этот договор оказался неудачей для Ирана, но его долгосрочный результат будет гарантировать отсутствие НАТО в Каспийском море и невозможность Соединенных Штатов устанавливать гегемонию над регионом». Он добавил, что «в обмен на принятие соглашения Россия позволит Ирану не только играть военную роль в Сирии, но и принимать участие в процессе восстановления страны, которая поможет им восстановить гегемонию над Сирией» [19].

«Один из принципов, принятый на саммите в Актау был об отсутствии иностранных военных кораблей, чему Иран и Россия придавали особое значение на встречах последних двух десятилетий» [17].

«Эта Конвенция чрезвычайно важна для стабильности в регионе, потому что ключевые принципы для поддержки региональной безопасности были согласованны», - сказал Притчин. «Главное относится к разрешению конфликтов и других вопросов в отношении военных баз на Каспийском море. Кроме того, ни одно из Каспийских государств не может использовать территорию для военных мер против соседних стран. В случае возможного конфликта, особенно в выражении американо-иранской напряженности, здесь нет опасности для Ирана со стороны размеров Каспия.

Критически, Конвенция Каспийского моря должна послужить стартовой точкой для дальнейшей региональной интеграции. В процессе диспута о том, как разделить водное пространство, сейчас приостановлено, 
но дальнейший прогресс может быть достигнут» [14].

Но, как было отмечено выше, в двусторонних договоренностях 1921 г., 1927 г., 1931 г., 1935 г., имеют место положения, применимые в настоящих условиях пятистороннего взаимодействия.

Далее данный принцип подчеркивается и развивается в дипломатическом сотрудничестве обеих стран, что демонстрируют ожидания и заверения в Нотах 1935 г.: «Принимая во внимание, что Каспийское море, рассматриваемое обоими Правительствами как море советское и иранское, представляет для Договаривающихся Сторон исключительный интерес, остается установленным, что оба Правительства примут необходимые меры для того, чтобы граждане третьих стран, находящиеся на их службе в портах этого моря, не использовали своего пребывания в этих портах для целей, выходящих за рамки возложенных на них обязанностей» [4, с. 138]. Данный принцип также актуален в достижении современных пятисторонних договоренностей.

При сопутствующих разногласиях Советской и Иранской сторон по вопросу о прохождении линии государственной границы между странами на отдельных участках, участники урегулируют пограничные вопросы на основе соблюдения взаимных интересов Сторон, придя к Соглашению, 1954 г. [4, с. 153].

Необходимо подчеркнуть, в условиях проведенной демаркации и ремаркации границы по водохранилищу Мильско-Муганской водозаборной плотины в 1955-1956 гг., осуществляемых по прямым линиям, оказались последним мероприятием по определению советско-иранской границы [4, с. 194].

Что предусматривалось в двустороннем Соглашении 1954 г.? Стороны заявили, что отныне все вопросы, связанные с прохождением линии государственной границы между Союзом Советских социалистических республик Ираном на всем ее протяжении являются урегулированными и что стороны не имеют друг у друга территориальных претензий» [4, с. 153].

Совместно с вышеуказанными принципами, тезис оказывается определяющим дальнейшее советскоиранское взаимодействие в регионе, вплоть до 1991 г. И в контексте изменения геополитических условий прошлые двусторонние договоренности по Каспийскому региону становятся неактуальными, в виду ликвидации одного из участников. Несмотря на принятие Российской Федерацией правопреемственности по международным договорам и обязательствам, вопрос обостряется ввиду появления новых потенциальных государств-правообладателей. И здесь возникают различные идеи и варианты по урегулированию проблемы государственно- го разграничения Каспийского моря.

С одной стороны, становится очевидной необходимость пятистороннего раздела вследствие наличия пяти прибрежных государств (Азербайджан, Иран, Казахстан, Россия, Туркменистан), где проблема состоит именно в принятии общей схемы разграничения совместного достижения общих критериев и принципов.

Но, с другой стороны, имеет место дебативная позиция о разделе $1 / 2$ части Каспия. Данное положение опирается на субъективное умозрительное толкование проблемы, где учет национальных интересов государства ограничен краткосрочными перспективами на фоне недооцененности сотрудничества, соседства, принципов соблюдении взаимных обязательств и, как следствие, получения взаимной выгоды.

Вопрос в том, что подразумевалось в этой позиции? Так в одном из прошлогодних выпусков Файненшиал Трибьюн появляется подобная трактовка вопроса «после распада Советского Союза начался спор о том, как правильно определить границу Каспия с Ираном, который владел 50\% моря» [16]. Кроме того, «человек, стоящий за принятием Ираном договора, диктатор, Верховный лидер Али Хоменеи. Он позволил Президенту Хасану Рухани подписать соглашение на половину территориальных вод и отказывается от их деления по 20\%, так страна предлагала на переговорах 1996 г., и по новому соглашению $11 \%$, которое, по сути, передает большинство природных ресурсов Ирана под принадлежность этих территорий морского дна Азербайджану» [19].

Подобные аспекты предопределяют чрезвычайную сложность в решении Каспийского вопроса для Тегерана. При детальном рассмотрении трансформации иранской позиции, необходимо подчеркнуть прямую зависимость от внешнеполитической ситуации и общественного мнения в стране. При этом иранская сторона в ходе пятисторонних переговоров наиболее четко придерживалась принципа раздела Каспия по срединным (медианным) линиям, согласно которым Иран рассчитывал на 13 - 20\% водоема.

Кроме того, «Иран оспаривал вопрос о том, что Каспий был озером, а не морем, но ни одна из четырех стран не согласилась. Почему это различие так важно? Если договор заключается в отношении моря, тогда он будет в области международного морского права, т.е. Конвенции ООН по морскому праву» [15]. Но, как известно, 12 августа 2018 г. на саммите в Актау сторонами была принята Конвенция о правовом статусе Каспийского моря, предоставившая новый формат решения вопроса о разграничении Каспия. «При этом Конвенция четко фиксирует цели такого разграничения исключительно для недропользования и обязывает стороны проводить 
его путем переговоров на основе международного права. Прибрежные государства при завершении делимитации получают полную юрисдикцию над ресурсами своего участка дна. Но правовой статус покрывающих вод отличен» [11], - как отмечал статс-секретарь, заместитель главы МИД РФ Г. Б. Карасин на кануне подписания документа. И здесь для Ирана добрососедские отношения и достижение договоренностей и $14 \%$ объекта разграничения на чаше весов перевесили «справедливый» национальный интерес и возможную (предполагаемую иранской стороной) 1/5 часть или 20\% [3].

Таким образом, основные принципы выявлены и закреплены в общем документе, но актуализируется проблема их практической реализации и, прежде всего, ратификации пятью подписавшими сторонами. Этап ратификации Конвенции о правовом статусе Каспийского моря имеет не только характер юридической процедуры, но воспринимается в качестве акта, подтверждающего договоренности. В настоящее время в 2019 г. и первой половине 2020 г. Исламская Республика Иран столкнулась с обстоятельствами разного рода, затягивающими процесс ратификации.

Во-первых, чрезвычайна важна внутриполитическая ситуация в стране. Как известно, в стране в конце 2017 начале 2018 гг. проходила волна протестов, которая была обусловлена рядом внутриэкономических и внешнеполитических причин, в том числе, участие Ирана и России в Сирийском вопросе. «Уходите из Сирии, подумайте о нас» [8] был один из лозунгов людей, выходивших на улицы. Здесь сотрудничающие государства олицетворяли волю высшего руководства странами, что противопоставлялось интересам простых иранцев, где при этом не наблюдалось очевидного лидерства. Протестная среда в результате была подавлена властями, но общественное мнение оставалось не согласным с внутриполитическим курсом и внешнеполитической деятельностью президента Хасана Роухани, что не помешало ему в сложившихся условиях принять участие в актаутском саммите, ознаменовавшим подписание Конвенции о правовом статусе Каспийского моря.

Протестный потенциал в стране перманентно тлел, достаточно было некоторых искр со стороны политической верхушки, чем и оказалась отмена правительством субсидий на бензин, что, естественно, привело к резкому росту цен на топливо. Так в ноябре 2019 г. страну захлестнули новые массовые волнения. Сам президент Роухани представляет реформистское крыло и его деятельность подразумевает проведение внутриэкономических преобразований, а также его внешнеполитический курс на партнерство оппонирует клерикалам.

Кроме того, сама структура формирования политической власти в стране подразумевает дисбаланс в при- нятии решений и их осуществлении. Согласно условиям Конвенции, в том числе подписанной президентом Ирана, провозглашены основные принципы, среди которых исключительные права прибрежных государств на Каспии, и достижение частных договоренностей в контексте двусторонних соглашений. Однако позиция Верховного лидера Ирана аятоллы Хаменеи несколько отличается. Еще в 2001 г. он говорил о том, что статус Каспийского моря должен определяться всеми прибрежными государствами и не может быть предметом двухсторонних договоренностей. По словам Хаменеи, судьба Каспия должна находиться только и только в руках прибрежных государств. «Никакая сила в мире не имеет право вмешиваться в каспийские дела или пытаться оказать на них влияние» [9]. Несмотря на давность высказанной Верховным лидером Ирана позиции в отношении Каспийского моря, нет причин утверждать о ее изменчивости. Так сложившаяся в Иране традиция формирования власти напоминает гору с двумя пиками, высота каждого из которых иногда меняется, но не существенно: факих и президент-реформист, их взгляды на решение внутренних и внешних проблем Ирана априори различны. Можно предположить, что внешнеполитическая деятельность президента Роухани, налаживание добрососедства и партнерства сравнивается с уступчивостью, а не геополитической целесообразностью.

Углубление внутриполитической дихотомии реформистов и консерваторов (принципалистов) демонстрируют парламентские выборы 2020 г. в Иране. В феврале состоялся первый тур выборов, по результатам которого победу одержало крыло консерваторов, при этом промежуточные итоги имеют неоднозначный характер. С одной стороны, победа принципалистов была предсказуема в виду внутриполитической, внутриэкономической ситуации в стране, разрастающегося протестного потенциала и оппозиционного общественного мнения, выражающегося как активными массовыми мероприятиями, так и пассивным отстаиванием гражданской позиции. Об этом свидетельствует чрезвычайно низкая явка на прошедших выборах, составившая 42\% [7]. С другой стороны, столь низкая явка может поставить легитимность состава нового правительства с лидерством консерваторов под сомнение.

Но в связи с эпидемиологической ситуацией в мире, и в Исламской Республике Иран в том числе, второй тур выборов, назначенный на апрель 2020 г., был перенесен ориентировочно на сентябрь этого же года. Кроме того, в 2021 г. пройдут очередные президентские выборы в Иране, в которых не сможет участвовать нынешний президент, и уже сейчас возникает вопрос о возможных кандидатах на должность. И победа принципалистов или реформистов не обязательно означает новые политические или социальные возможности, поскольку сложившаяся дуалистическая политическая система в Иране, 
как было отмечено выше, предопределяет использование своих полномочий различными властными структурами для сдерживания перемен.

Что касается вопроса о принятии и ратификации Конвенции о правовом статусе Каспийского моря в контексте внутриполитических обстоятельств, полагаем, Иран отодвинет осуществление акта ратификации на неопределенный срок. По всей видимости, причины для подобного решения оказываются самые разные, начиная от нестабильной внутриполитической обстановки, двойственности мнений политических лидеров, возможного неприятия со стороны общественного мнения до внешнеполитических обстоятельств и угроз.

Во-вторых, цепь внешних вызовов, с которыми сталкивается Иран в последние годы, сбивает фокус в работе над партнерскими отношениями с соседями по Каспию. Обострение отношений Ирана с США, в том числе выход США в мае 2018 г. из соглашения по иранской ядерной программе (Совместный всеобъемлющий план действий), организованное США убийство командующего спецподразделения «Аль-Кудс» Корпуса стражей Исламской революции генерал-лейтенанта Касема Сулеймани в январе 2020 г. разжигают проблему ядерной нестабильности в регионе. Личность самого Слеймани являлась чрезвычайно важной не только в военной обстановке, но и при политической расстановке сил в стране. «Его прочили в будущие президенты, он был гораздо влиятельнее нынешнего президента Хасана Роухани, к которому аятоллы относятся с недоверием, считая слишком либеральным. Он, по словам доктора Месамеда, определял внешнюю политику Ирана в большей степени, чем министр иностранных дел, аристократичный и улыбчивый Мохаммад Джавад Зариф» [2, с. 20].

По мнению военного эксперта В. Евсеева, распространение иранского ядерного вопроса будет означать усиление нестабильности в регионе и серьезный вызов российско-иранским отношениям и стратегическому диалогу, сложившемуся у Москвы и Тегерана именно в период президентства Хасана Роухани [10], подтверждением тому служит подписанная лидерами пяти государств Конвенция о правовом статусе Каспийского моря.

В дополнение в марте 2020 г. ВОЗ объявила ситуацию с распространением коронавируса COVID-19 пандемией [6], явление которого затронуло все сферы жизни десятков стран, в том числе Иран. Страна стала одним из мировых эпицентров, отличающихся высоким уровнем смертности от коронавируса [20]. Первый этап парламентских выборов в стране проходил уже в условиях выявления первых случаев заболевших, при этом власти пренебрегли первичными мерами предосторожности, оценив информацию о вирусе как о попытке внешних оппонентов сорвать проведение выборов [18].
К середине 2020 г. Иран продолжает бороться с волной заболевших, отодвигая решение внутриполитических вопросов на более поздние сроки, которые, полагаем, могут быть неоднократно скорректированы, ввиду масштабов распространения пандемии в Иране. По словам президента Хасана Роухани на заседании Национального штаба по противодействию коронавирусу в июле 2020 г.: «В течение последних 150 дней большое количество людей госпитализировано. В общей сложности в Иране на госпитализацию было помещено более 200 тысяч человек» [12]. Таким образом, возможно уменьшение интервала в сроках проведения второго тура парламентских выборов и выборов президента Ирана, которые должны состояться в 2021 г., т.к. полномочия X. Роухани в должности заканчиваются. Пандемия наводит свои коррективы в принятии политических решений, что, безусловно, относится и к политике Ирана по вопросу Каспийского моря.

При рассмотрении проблемы реализации Конвенции о правовом статусе Каспийского моря Иранской стороной выше были выявлены проблемы историко-политического характера, включая вопросы внутренней и внешней политики, вероятной смены кабинетов в виду расхождения авторитетных руководящих линий Верховного лидера Ирана и Президента страны. Историкогеополитический статус Каспия (Иран - Россия), национальные интересы стран, а также лидеров, которые их представляют, составляют основу для развития международных отношений в регионе Каспийского моря, на которой выстраивается комплекс вопросов, охватывающий разнообразные сферы. Так Хоссейнзадех В. в своей статье отмечает следующие области, которые захватывают интересы Ирана на Каспии: «экономическая сфера охватывает вопросы, имеющие отношение к экономике Ирана, в том числе углеводородные ресурсы, рыболовство, туризм; сфера безопасности - одна из важнейших предметов обеспокоенности Ирана является обеспечение безопасности и баланса сил в Каспийском регионе; правовая сфера - определение правового статуса Каспия и связанные с этим усилия, направленные на обеспечение максимальных интересов Ирана в Каспийском море; экологическая сфера - борьба с загрязнением и охрана экосистемы моря» [13, с. 225]. Отметим, что политико-правовую работу странами Каспийского региона в вышеуказанных областях активно проводилась, в контексте развязывания узла вопросов правовой сферы в условиях принятия «Конституции Каспийского моря». Но жизнеспособность документа требует его юридического многостороннего подтверждения и дальнейшего комплексного сотрудничества, которое замедлилось в виду складывающихся обстоятельств.

Нельзя оставить без внимания значение Каспийского моря в качестве крупного источника энергетических ресурсов прибрежных государств, в том числе Ирана. В 
контексте рассмотрения проблемы реализации Ираном юридических договоренностей по вопросу правового статуса Каспия необходимо отметить прямую взаимосвязь работы по добыче углеводородов Исламской Республикой на Каспии и состава иранского парламента. «Косвенно каждый нефтяной контракт на практике не только согласовывается с иранским парламентом, посредством включения доходов и расходов по таким контрактам в законы «О ежегодном бюджете», Парламент Ирана утверждает каждую нефтяную операцию по контракту посредством принятия ежегодного бюджета» [5, 31].

Выстроенная контрактная система по вопросам нефтеразработки, нефтедобычи и других углеводородных операций в Иране обеспечивает централизованный контроль отрасли. Ситуация в сфере эксплуатации нефтегазовых ресурсов Каспия и их вопрос их транспортировки к мировым рынкам требует огромных, в современных условиях многомиллиардных капиталовложений, не говоря уже о новейшей передовой технологии. Как отмечет С.М. Алиев еще в начале 2000- х гг., все это вызывает необходимость привлечения к разработке нефтегазовых ресурсов региона крупнейших транснациональных компаний [1, с. 533-534]. При этом авторы работы по правовому режиму недропользования в Иране, опубликованной в 2018 г., отмечают схожую тенденцию в современных условиях. «Контрактная (договорная) система недропользования в Иране, в отличие от российской лицензионной (разрешительной) системы с элементами государственно-частного партнерства на договорной основе, лежит в основе функционирования топливноэнергетического комплекса. Российские соглашения о разделе продукции и концессии в сфере недропользования можно сравнить с «дырками в сыре», а иранские нефтяные контракты с «сыром», на которые сбегаются зарубежные «мыши» [5, с. 43-44].

Полагаем, прежняя ориентированность нефтегазовой отрасли Ирана на Каспии имеет противоречивые тенденции в контексте достигнутых договоренностей по проблеме определения правового статуса Каспийского моря. И здесь вопрос эксплуатации нефтегазовых ресурсов олицетворяет одну из «частных» проблем, среди комплекса общих «неблагоприятных» обстоятельств внутри Ирана и за его пределами, которые оставляют вопрос ратификации Конвенции 2018 г., подразумевая «несвоевременность» его разрешения.

Кроме того, настоящая ситуация демонстрирует некоторые вопросы по Конвенции 2018 г., которые обнаруживались уже в контексте ее подписания. Во-первых, обобщающий характер, установление, согласование и закрепление принципов пятистороннего взаимодействия прикаспийских стран определили возникновение вопросов и дальнейшую работу. Во-вторых, установленный принцип разграничения Каспийского моря, требующий достижения дальнейших договоренностей сторон. По всей вероятности, здесь нет затягивания юридических процедур со стороны какого-либо государства-участника Актуатской Конвенции. И внутриполитические и международные условия доказывают необходимость тесной многоуровневой работы, интенсивной периодичности практических мероприятий и визитов, как в политической, экономической, так и научной, культурной областях с целью популяризации Каспия. Каспийское море, полагаем, следует рассматривать как географическое, историческое, экологическое поле национальных интересов прибрежных стран, а не только как достояния и ценного геополитического элемента. Под национальными интересами подразумеваем, прежде всего, безопасность и благосостояние населения, которые и становятся индикатором успехов или неудач политики и экономики на практике. Итак, мы приходим к следующим выводам. Во-первых, при рассмотрении принципов, закрепленных в Конвенции и их сопоставлении с положениями минувших двусторонних советско-иранских договоренностей, наблюдается своеобразная концептуальная преемственность во взаимодействии региональных государств. Во-вторых, в понимании и трактовке Конвенции находим двойственность, где, с одной стороны, документ есть триумфальный акт выражения политической воли, восприятия сторонами Каспия как целостного геостратегического объекта для реализации национальных интересов пяти государств. С другой стороны, документ представляет промежуточный пункт, требующий и признающий необходимость дальнейшего совещательного процесса. В-третьих, внутриполитическая обстановка, плюрализм мнений по решению Каспийского вопроса в самом Иране предопределяет длительность процесса ратификации документа.

\section{ЛИТЕРАТУРА}

1. Алиев С.М. История Ирана XX век. М.: Ин-т востоковедения РАН: Крафт +, 2004. 648 с.

2. Бейдер В. Игра без правил. Приведет ли ликвидация иранского генерала Касема Сулеймани к новой войне на Ближнем Востоке? [Электронный ресурс]: Огонек. №1. 13.01.2020. C. 20. URL: https://www.kommersant.ru/doc/4214696 (дата обращения: 20.05.2020).

3. Иран претендует на пятую часть Каспия [Электронный ресурс]: Коммерсантъ. №135. 25.07.2005. URL: https://www.kommersant.ru/doc/596003 (дата обращения: 24.05.2020).

4. Каспий: международно-правовые документы / сост. С.С. Жильцов, И.С. Зонн, А.Г. Костяной, А.В. Семенов - М.: Международные отношения, 2018.568 с. 
5. Манин Я.В., Язданимогадам М. Правовой режим недропользования в Исламской Республике Иран. /Уч. пособие. М.: Макс пресс, 2018. 67 с.

6. Невинная И. Глава В03 объявил пандемию коронавируса COVID-19 [Электронный ресурс]: Российская газета. 11.03.2020. URL: https://rg.ru/2020/03/11/ glava-voz-obiavil-pandemiiu-koronavirusa-covid-19.html (дата обращения: 14.05.2020).

7. Роухани прокомментировал рекордно низкую явку на парламентских выборах [Электронный ресурс]: MUA «Poccия сегодня». 23.02.2020. URL: https://ria. ru/20200223/1565127688.html (дата обращения: 23.03.2020).

8. «Смерть России» и «Моя жизнь - Иран»: к чему призывают протестующие в иранских городах [Электронный ресурс]: BBC NEWS Русская служба. 02.01.2018. URL: https://www.bbc.com/russian/features-42542346 (дата обращения: 26.06.2020).

9. Тегеран-2001. Иран вновь напомнил о своей позиции по Каспию. 07.05.2001. URL: https://neftegaz.ru/news/politics/326063-tegeran-2001-iran-vnovnapomnil-0-svoey-pozitsii-po-kaspiyu/ (дата обращения: 27.06.2020).

10. Торин А. Парламентские выборы в Иране: консерваторы побеждают [Электронный ресурс]: Международная жизнь. 02.03.2020. URL: https://interaffairs. ru/news/show/25543 (дата обращения: 26.05.2020).

11. «У Каспийского моря будет особый правовой статус». [Электронный ресурс]: Коммерсантъ. №141. 09.08.2018. URL: https://www.kommersant.ru/ doc/3707893 (дата обращения: 14.06.2020).

12. Хамдохов С. Роухани: В Иране коронавирусом заразились 25 миллионов человек [Электронный ресурс]: Российская Газета. 18.07.2020. URL: https:// rg.ru/2020/07/18/rouhani-v-irane-koronavirusom-zarazilis-25-millionov-chelovek.html (дата обращения: 03.08.2020).

13. Хоссейнзадех В. Политика Ирана в Каспийском регионе на современном этапе: итоги и перспективы [Электронный ресурс]: Проблемы постсоветского пространства. 2017. 4(3):221-228. C. 221 - 228. URL: https://www.postsovietarea.com/jour/article/view/125/124 (дата 0бращения: 28.07.2020).

14. Ballard B. More than Sea-mantics: the legal status of the Caspian Sea / Business Destinations. 22.03.2019. URL: https://www.businessdestinations.com/ destinations/more-than-Sea-mantics-the-legal-status-of-the-caspian-Sea/ (дата обращения: 10.05.2020).

15. Caspian Sea: five countries sign deal to end dispute. BBC News. 12.08.2018. URL: https://www.bbc.com/news/world-45162282 (дата 0бращения 12.05.2020).

16. Caspian States urged to boost Economic Cooperation / Financial Tribune. 12.08.2019. URL: https://financialtribune.com/articles/national/99377/caspian-statesurged-to-boost-economic-cooperation (дата обращения: 14.05.2020).

17. Kalehsar 0.Sh. Challenges and Opportunities toward Iran in the Convention on the legal status of the Caspian Sea /United World. 19.09.2019. URL: https://uwidata. com/5358 (дата обращения: 29.04.2020).

18. Mahmood N. Elections and coronavirus in Iran/The News on Sunday. 15.03.2020. URL: https://www.thenews.com.pk/tns/detail/629107 (дата обращения: 14.05.2020).

19. Taghvaee B. Caspian Sea: How Iran Gives Up Territory to Increase Influence / The Globepost. 23.08.2018. URL: https://theglobepost.com/2018/08/23/ (дата 06ращения: 28.04.2020).

20. Wright R. How Iran became a new epicenter of the coronavirus outbreak / THE NEW YORKER. 28.02.2020. URL: https://www.newyorker.com/news/our-columnists/ (дата обращения: 14.5.2020).

() Копылова Ирина Александровна (irochkakostenko@gmail.com).

Журнал «Современная наука: актуальные проблемы теории и практики» 